\title{
Recurrent Pituicytoma in a Pediatric Patient: A Case Report
}

\section{Pituicitoma recorrente em um paciente pediátrico: relato de caso}

\author{
Miguel Ángel Maldonado-Morán ${ }^{1}$ Jeisson Ospina ${ }^{2}$ Juan Vega ${ }^{3}$ Claudia Restrepo $^{4}$ Daniela Rico ${ }^{5}$ \\ Camilo Zubieta ${ }^{6}$ Pedro Penagos ${ }^{6}$
}

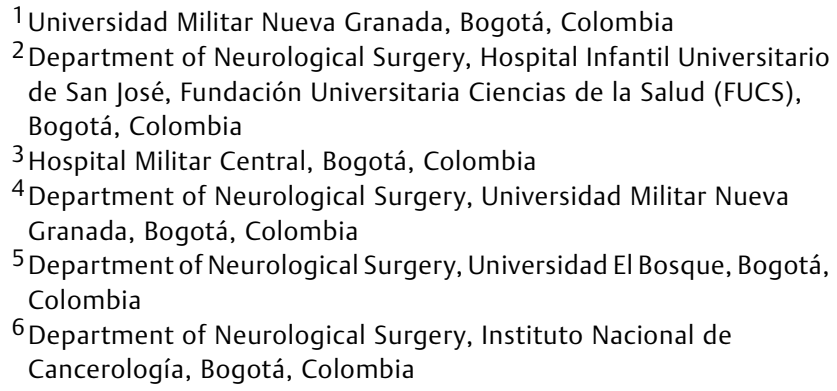

Address for correspondence Miguel Ángel Maldonado Morán, Universidad Militar Nueva Granada, Bogotá, Colombia (e-mail: miguel.mamoran@gmail.com).

Arq Bras Neurocir 2018;37:119-122.

\section{Abstract \\ Keywords \\ - pituicytoma \\ - pituitary tumor \\ - pituitary stalk tumors \\ - pediatric brain tumor}

\section{Resumo}

Palavras-chave

- pituicitoma

- tumor pituitário

- tumores da haste hipofisária

- tumor cerebral pediátrico
Pituicytoma is a rare tumor that arises from the glial cells of the neurohypophysis. For a long time, it was believed that pituicytomas only appeared in adults. Currently, at least three cases of this entity occurring in children have been reported in the literature. The aim of the present report is to describe the case of a 5-year-old girl who presented to the emergency department with visual disturbances, and the diagnosis was a recurrent pituicytoma. Therefore, the clinical presentation, the radiological features of the tumor, and the corresponding surgical management are described. Additionally, a brief review of the management of this unusual entity was performed.

O pituicitoma é um tumor raro que surge das células gliais da neurohipófise. Durante muito tempo, acreditou-se que os pituicitomas só aparecessem em adultos. Atualmente, pelo menos três casos desta entidade ocorrendo em crianças foram relatados na literatura. O objetivo do presente artigo é descrever o caso de uma menina de 5 anos que chegou à emergência com distúrbios visuais, e o diagnóstico foi um pituicitoma recorrente. A apresentação clínica, as características radiológicas do tumor, e o correspondente manejo cirúrgico foram, portanto, descritos. Além disso, foi realizada uma breve revisão do tratamento desta entidade incomum. received

January 28, 2018

accepted

April 24, 2018

published online

June 11, 2018
DOI https://doi.org/

10.1055/s-0038-1660465. ISSN 0103-5355.
Copyright $\odot 2018$ by Thieme Revinter

Publicações Ltda, Rio de Janeiro, Brazil
License terms

(c) (i) $\ominus$ (\$) 


\section{Introduction}

The term pituicytoma refers to an infundibuloma that arises from the glial cells of the neurohypophysis and/or the pituitary stalk, also called pituicytes. ${ }^{1-3}$ In the literature, there are less than 80 cases reported that meet all of the World Health Organization's (WHO) classification criteria for this type of tumor. ${ }^{3}$ There is no clinical guideline for the diagnosis and management of this rare entity. The 2016 WHO classification of tumors of the central nervous system classifies the pituicytoma as a grade 1 (borderline, unspecified, or uncertain behavior) tumor. ${ }^{4}$ In the classical description, the pituicytoma has been considered a condition that occurs only in adults, ${ }^{2}$ so in cases like the one reported in the present study, in a pediatric patient, the diagnosis becomes very challenging. To our knowledge, there are only four cases described in the pediatric population, ${ }^{2,5-7}$ and we did not find any reports about the management of recurrent pituicytoma in a pediatric patient.

\section{Materials and Methods}

A complete description of the pertinent information from clinical records was made, all of the available histologic samples were taken, and all diagnostic imaging exams were performed. The patient was admitted to the Instituto Nacional de Cancerología, in Bogota, Colombia. A complete multidisciplinary assessment was performed by pediatricians, a pediatric oncologist, pediatric endocrinologists and neurosurgeons. A preoperative magnetic resonance imaging (MRI) of the brain and of the sellar region as well as a complete endocrinology evaluation were performed.

The present work is based on the general principles of human research ethics set forth in the Helsinki declaration; the purpose of the present study is to obtain scientific knowledge for a better diagnosis and a more precise evaluation that may eventually help to predict or improve the neurological outcome of these patients. It adopts resolution $8,430 / 1993$ of the Colombian Ministry of Health, and is based on the definitions of risk contained in the corresponding article of that law, for which it classifies the present study as a risk-free research, since it is a retrospective study based on medical records. Authorization was requested to the parents of the patient to include her information in the present study, preserving her identity both in the analysis of the information and in the images presented. The informed consent was fully filled by her parents for the publication of clinical and radiologic information in this manuscript.

\section{Case Report}

This is a case of a Hispanic 5-year-old girl who presented to the emergency department with a 3-month clinical course of decreased visual acuity and nystagmus. A contrast-enhanced MRI of the head was performed, showing a tumor in the sella turcica. Tumor resection was indicated, but the parents rejected any surgical intervention in her first consultation. Two years later, the patient presented again to the emergen- cy department in a different institution with bilateral amaurosis and aggressiveness. Her parents accepted surgical treatment in the second consultation, and an urgent resection was performed via frontal craniotomy, completing a total cyst drainage with resection of the nodular component. A non-conclusive pathology report was obtained at first. In the immediate postoperative period, there was no improvement in her symptoms. After a few months, the patient was referred to the Instituto Nacional de Cancerología for multidisciplinary management with pediatric oncology and oncologic neurosurgery. Upon admission to our institution, a fistula containing cerebrospinal fluid was detected. Menstrual disorders, as well as obesity and early gynecomastia were also recorded. A contrast-enhanced MRI of the brain was performed. The tumor was hypointense in T1, hypointense in T2, with heterogeneous enhancement with gadolinium of the nodular component. A cystic component was also noted within the anterior cranial fossa (-Fig. 1).

A surgical decision-making group, including the pediatric oncology, endocrinology, and neurosurgery departments concluded that the first diagnostic possibility was an adamantinomatous craniopharyngioma, and a new surgical resection should be performed. Consequently, the patient underwent a new surgical procedure, with a right transcranial subfrontal approach. A near gross total resection was performed, achieving 95\% cytoreduction of the solid component (-Fig. 1). Pathology results reported an astrocytic glioma (grade 1 of the 2016 WHO classification), consistent with a pituicytoma (-Figs. 2, 3). Immunochemistry samples demonstrated endomysial antibodies (EMAs) and chromogranin negativity, with a proliferation index $\mathrm{K}_{\mathrm{i}^{-}}$ 67 lower than 3\%. Furthermore, the adjuvant treatment with radiotherapy was completed. Postoperatively, the patient persisted with central hypothyroidism and hypocortisolism, receiving hormonal substitution. In the clinical examination, improvement in visual acuity and better behavior were noted, with a Lansky/Play performance scale score of $80 \%$.

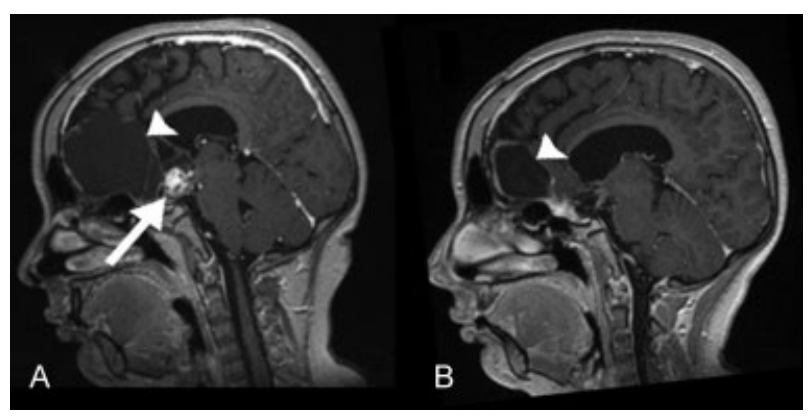

Fig. 1 (A) Preoperative contrast-enhanced magnetic resonance imaging (MRI) of the head showing a recurrent pituicytoma in a pediatric patient. A sealed lesion with a large solid component (arrow), with heterogeneous enhancement, is noted. An interhemispheric frontal cyst is also observed (arrowhead). (B) Postoperative contrast-enhanced MRI of the head in the two-year follow-up. Disappearance of the suprasellar interhemispheric solid component is observed. The partial residual cystic component of the interhemispheric frontal lesion is denoted (arrowhead). 


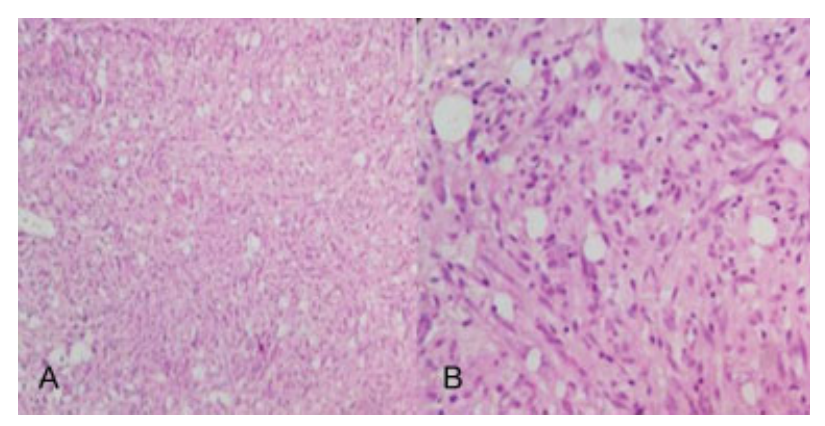

Fig. 2 These histological samples (A, panoramic view; B, zoom view) show tumor cells with glial differentiation, with the characteristic fusiform cell proliferation, with a fibrillary fundus and the presence of calcifications, without atypia or mitosis.

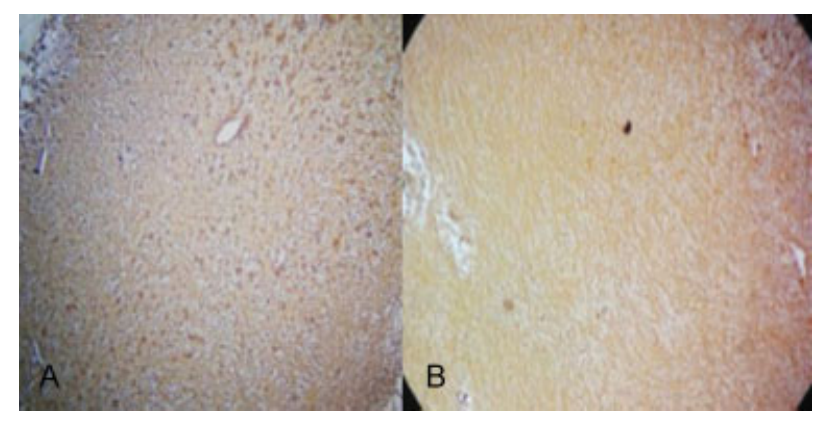

Fig. 3 Immunochemistry samples showing (A) S100 positivity and (B) glial fibrillary acidic protein (GFAP) positivity, consistent with a pituicytoma.

\section{Discussion}

Pituicytomas are tumors of the nucleated cells that arise from the pituitary neurohypophysis and the infundibulum (pituicytes), which are located in the sellar and suprasellar regions, ${ }^{8}$ and are grouped as tumors of the sellar region. ${ }^{4}$ They occur predominantly in adults, between the 4 th and the 5 th decades of life, and have a slight preponderance on males $(1.3: 1){ }^{3}$ Moreover, a pituicyte is a glial cell located in the neurohypophysis near the hypothalamus. It is closely related to multiple vessels, and has different axon connections. It is believed that pituicytes play a role in the regulation of hormonal release and secretion of endocrine cells. ${ }^{8}$ Pituicytes also serve as a support for oxytocin- and vasopressin-producing neurons. There are five types of cells: oncocytic, major, ependymal, dark and granular. ${ }^{5,9}$ The neoplasms arising from these cells are considered benign lesions with a progressive course, with no reports of malignant transformation. ${ }^{5}$

Pituicytomas are very rare and, to the best of our knowledge, there are only 78 cases of pituicytomas reported in the literature. Only four of them occurred in the pediatric population. A total of 3 occurred in girls, and 1 in a 13year-old boy with a giant pituicytoma. ${ }^{2}$ The youngest case is that of a 7-year-old girl. ${ }^{5}$ To date, the patient in our report is the youngest patient with a pituicytoma reported in the literature, being the fifth case of a pediatric pituicytoma.
The clinical presentation in these patients is attributable to the local compression of the tumor. The most common symptoms include headache, visual field disorders and visual alterations due to compression of the chiasm. Lower stalk or posterior pituitary lesions produce temporary diabetes insipidus and endocrine disorders like hypopituitarism, sexual dysfunction, menstrual disorders and gynecomastia., ${ }^{4,9}$ Our case presented with menstrual disorders, obesity and gynecomastia, which are symptoms with an incidence of presentation of $3,8 \%, 1 \%$ and $9 \%$ respectively, ${ }^{2}$ which makes our report even more interesting.

The pathologic profile is marked by a proliferation of fusiform bipolar elongated cells, with low cell proliferation, low atypia, and paucity of mitotic figures. Pituicytoma cells tend to be swirling. The literature shows that many cells are positive for vimentin. ${ }^{3}$ Additional diffuse S-100 protein inmunoreactivity and glial fibrillary acidic protein (GFAP) staining are usually present. The anterior pituitary hormone markers are mostly negative, and they are used for differential diagnosis with pituitary adenomas. ${ }^{2,8}$ These tumors are also negative for EMA and chromogranin. The proliferation index $\mathrm{K}_{\mathrm{i}}-67$ is low, usually below $3 \%{ }^{10}$

Regarding the imaging features, an adequate imaging protocol is mandatory to characterize these tumors. The first step is to perform a computed tomography (CT), which usually shows an isointense mass located within the sellar or suprasellar regions, without evidence of calcification or bony erosion, with strong enhancement after contrast administration. ${ }^{2}$ Nevertheless, MRI is the diagnostic modality of choice. Mostly, the tumors are presented as solid, welldefined oval masses, located in the posterior sellar region. They show isointense signal on T1 and low hyperintense signal on T2. After contrast administration, a homogeneous or heterogeneous pattern of enhancement can be present. ${ }^{1,3,11}$ The location within the posterior aspect of the pituitary gland, clearly displacing the adenohypophysis forward, is characteristic. In $50 \%$ of the cases the location is purely suprasellar, followed by $40 \%$ with suprasellar extension. ${ }^{1}$ This sellar mass is challenging to distinguish from other lesions. According to the review by Covington et $\mathrm{al}^{12}$ only pituicytomas can be purely intrasellar. The Differential diagnoses include pituitary adenoma, pilocytic astrocytoma, meningioma, granular cell tumors, craniopharyngioma, hamartoma and germinoma. ${ }^{1,4,11}$

The gold standard treatment of these tumors is surgery. ${ }^{1}$ The aim of the surgery is to perform a total resection of the tumor. There is a very low recurrence rate $(4,3 \%)^{8,9}$ Chakraborti et al showed no recurrence after gross total resection in a follow-up period varying from 3 months to 7 years. ${ }^{5}$ In their review, they reported 67 procedures, with the trans-sphenoidal approach being the most common, followed by the frontotemporal approach. They described the tumors and demarcated solid pink masses. Gross total resection was not achieved due to hypervascularity, which remains the most common intraoperative challenge. ${ }^{5}$ Since these tumors are vascular, preoperative embolization of arterial feeders has been reported, in order to facilitate total removal. ${ }^{13}$ The most common postoperative 
complications are diabetes insipidus, hypopituitarism, visual deficit and hypotiroidism. ${ }^{2}$

Most tumors behave in a benign fashion if total resection is performed. The cases with gross total resection do not show recurrence. ${ }^{14}$ Nevertheless, the data in the literature is limited. ${ }^{8,9}$ Some authors estimate $39 \%$ of recurrence in patients who underwent subtotal resection over periods ranging from 5 months to 7 years. There is restricted experience regarding adjuvant chemotherapy or radiation therapy in the management of cases undergoing complete resection, whereas controversy exists regarding cases with partial removal, as well as regarding the benefit of radiotherapy because of the high rates of recurrence. ${ }^{2}$ A close follow-up with MRI for patients with residual tumors is recommended. ${ }^{2}$ Stereotactic radiotherapy has been considered for cases with aggressive behavior, or when a second surgical approach is unachievable because of size and location. Besides, the side effects of radiation, which include hypopituitarism, optic neuropathy, necrosis, vascular damage, and induction of other types of brain tumors, always have to be considered. ${ }^{1}$ No clinical guideline of management for recurrent pituicytomas exists. We believe that a transcranial subfrontal/frontotemporal approach is a feasible option for recurrent cases. In our case, the patient recovered from her visual symptoms, and only a cystic component of the lesion persisted after the second intervention. Complimentary radiotherapy was not needed, though. The behavior of this residual cyst remains unclear, and additional follow-up is needed.

\section{Conclusions}

A Pituicitomas are a very rare type of tumors, even more in pediatric patients. As this entity is not common in young patients the diagnosis could be very challenging, but with the correct histopathology tools we could did it. Surgery is the gold standard treatment. We present in this report a case of adequate surgical treatment with a frontotemporal approach for a recurrent pituicytoma in a very young patient, the youngest (to our knowledge) in the literature.
Conflicts of Interest None to declare.

\section{References}

1 Teti C, Castelletti L, Allegretti L, et al. Pituitary image: pituicytoma. Pituitary 2015;18(05):592-597

2 Tian Y, Yue S, Jia G, Zhang Y. Childhood giant pituicytoma: a report and review of the literature. Clin Neurol Neurosurg 2013;115(10): 1943-1950

3 Ellis JA, Tsankova NM, D'Amico R, et al. Epithelioid pituicytoma. World Neurosurg 2012;78(1-2):E1-E7

4 Louis DN, Perry A, Reifenberger G, et al. The 2016 World Health Organization Classification of Tumors of the Central Nervous System: a summary. Acta Neuropathol 2016;131(06): 803-820

5 Chakraborti S, Mahadevan A, Govindan A, et al. Pituicytoma: report of three cases with review of literature. Pathol Res Pract 2013;209(01):52-58

6 Yilmaz Ö, Turan A, Yiğit H, Duymuş M, Koşar U. Case of pituicytoma in childhood. Childs Nerv Syst 2012;28(01):11-12

7 Cambiaso P, Amodio D, Procaccini E, et al. Pituicytoma and Cushing's Disease in a 7-Year-Old Girl: A Mere Coincidence? Pediatrics 2015;136(06):e1632-e1636

8 Kowalski RJ, Prayson RA, Mayberg MR. Pituicytoma. Ann Diagn Pathol 2004;8(05):290-294

9 Yang X, Liu X, Li W, Chen D. Pituicytoma: A report of three cases and literature review. Oncol Lett 2016;12(05):3417-3422

10 Brat DJ, Scheithauer BW, Staugaitis SM, Holtzman RN, Morgello S, Burger PC. Pituicytoma: a distinctive low-grade glioma of the neurohypophysis. Am J Surg Pathol 2000;24(03):362-368

11 Hammoud DA, Munter FM, Brat DJ, Pomper MG. Magnetic resonance imaging features of pituicytomas: analysis of 10 cases. J Comput Assist Tomogr 2010;34(05):757-761

12 Covington MF, Chin SS, Osborn AG. Pituicytoma, spindle cell oncocytoma, and granular cell tumor: Clarification and metaanalysis of the world literature since 1893. AJNR Am J Neuroradiol 2011;32:2067-2072

13 Furtado SV, Ghosal N, Venkatesh PK, Gupta K, Hegde AS. Diagnostic and clinical implications of pituicytoma. J Clin Neurosci 2010;17(07):938-943

14 Pirayesh Islamian A, Buslei R, Saeger W, Fahlbusch R. Pituicytoma: overview of treatment strategies and outcome. Pituitary 2012;15 (02):227-236 